\title{
JOAQUIM DE CARVALHO \\ E A FENOMENOLOGIA
}

\author{
José Maurício de Carvalho \\ Departamento de Filosofia e Métodos da UFSJ
}

\section{Considerações iniciais}

Os estudos sobre Edmund Husserl e a filosofia fenomenológica ganharam importância crescente no decorrer do século XX. A fenomenologia representa, desde então, importante esforço de compreensão do homem e dos problemas consagrados pela tradição filosófica. Vivia-se, no século passado, um momento de crise social e política, de revoluções e guerras, de inconformismo e perplexidade com os rumos tomados pela civilização pensada sob a égide da ciência e desencanto com as crenças religiosas. Husserl esclareceu que essa crise da civilização não significava rejeitar os resultados de sucesso da ciência, mas os efeitos da concepção cientificista do positivismo que a afastava de sua significação humana.

Essa situação pedia uma nova forma de tratar os fundamentos da existência humana capaz de recolocar o sentido da responsabilidade pessoal e liberdade num mundo em transformação e desiludido com os resultados dos conflitos bélicos. Edmund Husserl começou a enfrentar tais dificuldades procurando uma forma diferente de tratar a consciência humana. Esperava com a nova concepção süperar simultaneamente o objetivismo materialista e o subjetivismo transcendental. O filósofo desejava também lidar melhor com a historicidade do homem, suas contradições e dramas. O entendimento do sentido trágico da vida, a consciência dos riscos que as escolhas representam reforça a noção de historicidade do homem, um ente que se faz no tempo e que resulta de suas escolhas.

A fenomenologia, portanto, pôs em causa o conhecimento humano e a redução que o positivismo trouxe às ciências quando essa retirou a responsa- 
bilidade do homem construir um sentido pessoal para sua existência. Tal prática retirou o foco da responsabilidade que temos com nossas escolhas quando exercitamos a liberdade e experimentamos a angústia de nosso modo de viver ao constatar que construímos, sem certezas, o sentido de nossa vida.

Joaquim de Carvalho assumiria em seus estudos as preocupações fenomenológicas, a consciência é responsável pelo que somos e ela não só conhece e hierarquiza os seres, mas indica preferência, como escreveu em "Com a razão nas mãos", capítulo II do seu Pensamento Político (1989):

Se for a consciência de cada um que diz às coisas o sim e o não, se o seu dizer é incoercível e sem apelação decisiva, tudo o que constitui o universo - coisas, fenômenos, ideias e valores só valem para a personalidade espiritual do homem e existe subordinando aos valores supremos da pessoa, os valores morais. (p. 264)

A meditação de Edmund Husserl voltada para a busca do fundamento da ciência e para entender o vivido originário, tornara-se leitura obrigatória nas primeiras décadas do século passado. Os escritos husserlianos foram traduzidos para diversos idiomas. Joaquim de Carvalho integra esse movimento de difusão da fenomenologia escrevendo longa introdução à tradução portuguesa do livro Filosofia como ciência de rigor de Husserl. A obra foi precursora do movimento fenomenológico em Portugal, conforme observa António José de Brito no capítulo que escreveu no livro $O$ movimento fenomenológico em Portugal e no Brasil (2010):

A tradução portuguesa, de responsabilidade de Albin Beau, do célebre estudo de Husserl Filosofia como ciência de rigor, foi [...] sinal precursor da aparição de um bom número de obras de vulto acerca da fenomenologia. A tradução vem precedida de um longo prefácio de Joaquim de Carvalho. (p. 22)

Somente esse trabalho já significaria muito para os estudos fenomenológicos. No entanto, o contato de Joaquim de Carvalho com a fenomenologia influenciou a forma como ele pensou o filosofar, em especial a maneira de fazer a história da filosofia. É na fenomenologia que ele se inspira para pensar a tradição filosófica superando os problemas da interpretação hegeliana. É essa a tese defendida em História da Filosofia e Tradições Culturais, um diálogo com Joaquim de Carvalho (2001) que retomamos aqui.

\section{A reconstrução da tradição filosófica por inspiração fenomenológica}

Como tratar de questões culturais como as da história da filosofia de um modo rigoroso? Uma forma de fazê-lo é considerar as lições deixadas por 
Edmund Husserl sobre a consciência intencional e o mundo vivido, como dissemos no livro O Homem e a Filosofia (2007):

Foi Husserl quem introduziu este esforço de compreensão na filosofia de nosso tempo. Seu propósito foi compreender o mundo como fenômeno, isto é, mostrar como ele se apresenta à consciência e permite a formação de uma unidade de sentido. Fenômeno é, pois, o que emerge na consciência, aquilo que pode ser apreendido antes de qualquer reflexão. Não há dúvida que há muitas coisas em torno de nós, porém não era objetivo de Husserl ir até as coisas mesmas, mas mostrar que o que denominamos mundo é o modo como elas se apresentam à consciência. Este elemento de certificação cognoscitiva é o que Husserl denominou de mundo vivido. Ele denominava de mundo vivido o solo de nossa presença sensível e social vivida como sujeito encarnado. (p. 30)

Entendemos que a forma como Joaquim de Carvalho pensa a tradição filosófica antes referida o projeta como dono de uma das mais significativas contribuições ao movimento fenomenológico português. A questão não é saber se Carvalho é um exímio conhecedor de Hegel, como parece preocupar-se António José de Brito no estudo mencionado no tópico anterior, mas perceber se ele identifica adequadamente no hegelianismo os problemas que o movimento fenomenológico percebeu e procurou resolver. Parece-nos que assim ocorre. A revisão que ele fez do modo hegeliano de enxergar a história da filosofia não retira de Hegel o mérito de haver deixado importantíssima contribuição para o estudo da tradição filosófica, certamente das mais importantes constituída nos tempos modernos.

A interpretação hegeliana da história da filosofia indicava a relatividade de todas as filosofias, problema que o filósofo resolveu identificando História e Razão. Edmund Husserl notou que essa identificação culminava num historicismo absoluto que pedia uma justificativa rigorosa da reflexão filosófica e uma separação entre os conceitos, como já mencionamos em outra oportunidade (2001): "Joaquim de Carvalho explicou que Husserl tinha razão ao separar espírito e história, mesmo reconhecendo que esta última é o espaço do espírito e que aquele possui história." (p. 61)

A formulação husserliana da consciência e dos riscos da existência propicia reconhecer a sua historicidade, preservando a autonomia e individualidade do espírito humano, conforme indicamos no artigo Filosofia Política; Joaquim de Carvalho e a liberal democracia (2000): "o pensador lusitano não apenas fez do homem o ponto de partida da vida social, como nele reconheceu uma realidade que é única entre todos os entes" (p. 105). Joaquim de Carvalho associa historicidade e risco, incorporando o que afirmou a respeito Paul Ricoeur, na introdução à Filosofia como ciência de rigor (1981):

O próprio sentido trágico da história inclinou Husserl a pensar historicamente. Suspeito aos nazis por não-ariano, por pensador científico, mais fundamental- 
mente, por gênio socrático [...] o velho Husserl não podia deixar de descobrir que o espírito tem uma história que importa a toda história, que o espírito pode estar doente e que a história é para o próprio espírito o lugar de perigo, da perda possível. (p. 492)

A própria história da filosofia permite entender o aspeto dramático que acompanha a existência humana em todos os tempos revelando, afirma-o em Antero de Quental e a filosofia de Hartmann (1992): "o drama íntimo e solitário da luta de sentimentos opostos" (p. 411) que acompanha o português como de resto todo homem daquele tempo.

A historicidade do homem é uma referência importante para perceber o movimento da consciência e chegar a um filosofar válido sobre os temas da cultura.

O filosofar é individual, disse Husserl, sustenta-se na experiência concreta, vivida, e somente como tal consegue dar compreensibilidade ao saber cultural, que não é o conhecimento abstrato do objeto porque depende da vida que os ordenou. ${ }^{1}$

Edmund Husserl superou o relativismo presente no historicismo absoluto de Hegel chamando atenção para os problemas que emergem na consciência. Sem princípios claros de verdade, avaliou, o historicismo absoluto de Hegel se torna relativismo. É quando e no modo de problematizar que homem e mundo deixam de ser experiências isoladas e ganham significação como expressão da consciência intencional, isto é, como problema pensado numa dada situação. A intencionalidade é um conceito importantíssimo na fenomenologia. Husserl entende por intencional o fato de a consciência estar envolvida com algo que a mobiliza e ela passa a querer, a sentir e a conhecer esse algo. Emmanuel Lévinas identifica um aspeto fundamental da intencionalidade, a consciência é que dá sentido ao mundo, afirma (1949): "intencionalidade é essencialmente o ato de emprestar um sentido" (p. 22). É dando ênfase aos problemas que o historiador da filosofia procura chegar ao sentido que o filósofo procurou dar às questões. Ao mesmo tempo o historiador da filosofia enfrenta as exigências de rigor intelectual e de fundamentação que a tradição filosófica exige dos que aceitam o desafio de filosofar. O propósito husserliano de fazer uma filosofia rigorosa se exprime na história da filosofia na busca, afirma-o em "Discurso pronunciado em Braga" (1981): "de atitudes e juízos transtemporais, isto é, atitudes que retomam e repensam os problemas e respostas fora e independentemente do hic et nunc das categorias da história" (p. 430).

Esse procedimento rigoroso que Joaquim de Carvalho incorporou aos estudos de história da filosofia remonta a Husserl, conforme ele esclarece na Introdução que preparou à Filosofia como ciência de rigor. A atitude metodo-

${ }^{1}$ Carvalho, 2001, p. 62 
lógica que a fenomenologia inspira permite superar o relativismo historicista de Hegel, cujo ideal é o todo da história, ao contrário do propósito de Husserl. É o que diz Carvalho (1981): "Husserl considerava a filosofia, por essência, uma ciência dos inícios verdadeiros e do radical, cujo impulso indagador não é das filosofias que deve partir, mas sim das coisas e dos problemas" (p. 495). Ao invés de olhar as filosofias como respostas ao espírito do tempo, como propôs Hegel, antes era fundamental entender os problemas que elas buscavam responder, entendendo de dentro da meditação o que mobiliza o filósofo.

$\mathrm{O}$ estudo da tradição filosófica por Joaquim de Carvalho não perde de vista a historicidade da consciência, mas respeita a dinâmica própria do filosofar pela ênfase conferida aos problemas. Essa é a estratégia com a qual ele supera a ideia de uma razão absoluta que se descobre no processo histórico para se concentrar na busca de fundamento do saber filosófico pelos tempos afora.

A ênfase nos problemas se apresenta no dado imediato da consciência dos filósofos tomado como fenômeno percebido. Essa forma de se referir aos desafios enfrentados pelos filósofos não pressupõe uma consciência geral ou uma entidade suprapessoal intuída pelo sujeito cognoscente, pois não há como pensar um sentido para o fenômeno caso ele faça parte de um todo fenomênico.

A fenomenologia de Husserl trata da consciência vivente e atual. Ao usá-la como referência para tratar do que já foi pensado num outro tempo deve sê-lo como consciência de um problema vivido e pensado, conclui Joaquim de Carvalho. O professor coimbrão apreende perfeitamente o modo como Husserl pensa o filosofar e o utiliza para compreender como as pessoas pensavam, diferenciando esse procedimento transcendental do modo kantiano de pensar e da forma hegeliana de fazer história da filosofia. Transcendental no sentido fenomenológico é o que dá sentido. Ele explica essa questão na introdução que preparou ao livro de Husserl (1981):

Assim entendido a fenomenologia tem um significado profundamente diverso da hegeliana Fenomenologia do Espírito, que no pensamento de seu genial criador significava a desenvolução das fases pelas quais o espírito se eleva da sensação individual à razão universal, e a investigação fenomenológica que lhe é própria não se apresenta como investigação psicológica, no sentido experimental, introspetivo ou extrospectivo, nem tão pouco transcendental no sentido kantiano, cujo método pressupõe a existência de algo cujas condições de possibilidade a priori são criticamente indagadas. (p. 497)

A diferença na forma de conceber o movimento da consciência revela que para a fenomenologia o ato psíquico é expressão da consciência intencional, isto é, a consciência é sempre consciência de algo, uma referência ao objeto com o qual se relaciona, mas não pressupõe uma evolução de formas sensíveis até elementos gerais de uma razão universal. A forma husserliana de filosofar 
estabelece um parâmetro diverso do hegeliano para examinar a tradição filosófica porque Husserl trata de modo singular o ato cognitivo. A consciência humana é histórica e poderia ser afetada pela experiência temporal, mas esse aspeto pode ser superado por outro elemento da fenomenologia: a epoché ou suspensão do juízo. Isso é possível colocando entre parênteses o mundo dos objetos e as impressões psicológicas que eles provocam. Para Husserl, a suspensão do juízo coloca em contato com a transcendência e propicia olhar para cada filosofia com uma atitude puramente descritiva. A redução fenomenológica afasta o que não tem sentido. A forma fenomenológica de olhar a tradição filosófica a coloca não só contra a leitura hegeliana da história da filosofia, mas contra toda proposta historicista como a positivista, que foi influenciada pelo historicismo dialético de Hegel. Também está distante de qualquer caminho percorrido pela ciência, conforme esclarece Joaquim de Carvalho (1981):

A marcha da sua análise não seguiu nenhum destes caminhos, que são os caminhos do investigador científico, da Psicologia e das ciências em geral, e do epistemologista de sentido tradicional, porque aplica a todos estes temas e problemas a epoché, isto é, coloca tudo entre parênteses, como diz nas Ideias. (p. 498)

O afastamento de Hegel e da psicologia científica o afasta do modo como o positivismo trata a consciência humana. Assim ocorre, Carvalho explica em Saber e Filosofar, porque "realidade não se oferece apenas sob a forma de objetos tangíveis e percetíveis, isto é, sob a forma de exterioridade" (p. 357) como entende o positivismo. O mundo da consciência não foi investigado por Augusto Comte porque o filósofo o desconsidera, reduzindo-o à coisa e privando-o de sua singularidade. Isso não é tudo, "a valorização da ciência pelo positivismo, como já escrevemos em outro lugar, trouxe, como contrapartida, a eliminação, a despreocupação com a subjetividade".2

A evolução da consciência não se expressa nos momentos mencionados por Comte, avalia Joaquim de Carvalho, porque os objetos da consciência permitem identificar regiões ontológicas diversas que afastam, por exemplo, a matéria do pensamento, a consciência afetiva dos mecanismos da vida. Lembramos que Husserl procurou superar a naturalização do espírito, explicando de maneira diversa do positivismo a forma como o sujeito e objeto se relacionam. Lévinas trata especificamente dessa preocupação fenomenológica do seguinte modo (1949):

Não é pelo fato de refletir-se que se define a relação entre o objeto e o pensamento, mas pelo sentido do objeto e de sua existência. (p. 27)

\footnotetext{
${ }^{2}$ Carvalho, 2001, p. 39
} 
A separação das regiões ontológicas permitiu a Husserl superar as psicologias comportamentistas já que o homem não participa apenas de um bloco da realidade, a saber: o material, ligando-se ao mundo exclusivamente pelas relações de causalidade. A consciência psicológica não é de natureza física, implica responsabilidade e sentimentos. Os sentimentos, por sua vez, não estão presentes em mim como um produto químico. Podem estar em diferentes graus e dependem da forma com lido com os fenômenos para que eles me causem medo ou não. No entanto, a descoberta dos blocos da realidade não tem consequência apenas nos estudos psicológicos, mas permite olhar a tradição filosófica de uma forma especial. Numa história da filosofia de inspiração fenomenológica não falamos de evolução linear como pressupôs uma psicologia naturalista ou o historicismo radical de inspiração positivista, afirma Joaquim de Carvalho no seu estudo sobre Husserl:

A existência de regiões ontológicas diversas, correspondendo a cada uma delas, essências hiléticas e formais que fundamentam as ciências relativas às diversas regiões, arruína pela raiz a naturalização das ideias e da consciência e põe a claro a percepção fenomenológica do ser, a qual abre caminho imenso de amplas intelecções dos mais rigorosos e decisivos para toda a filosofia ulterior e converte a Fenomenologia em ciência radical, a cujas ontologias regionais ou fenomenológicas particulares, as ciências objetivadas vão buscar os respetivos fundamentos. (p. 502)

As regiões ontológicas indicam que não faz sentido falar de evolução de um paradigma religioso ou metafísico para uma mentalidade naturalista ou positivista porque se está tratando de aspetos diferentes do real. O historicismo de Comte pressupõe tal evolução, como o de Hegel identifica história e razão. O desafio quando se examina sistemas passados é de recolocar na consciência do investigador o problema vivido pelos filósofos de outros tempos e superar as interpretações relativas que ele teve da parte de outros estudiosos ou mostrar os limites da reflexão.

A influência de Husserl levou Joaquim de Carvalho a admitir sucessivos retornos de aprofundamento às filosofias do passado, livrando a história da filosofia de uma filosofia da história concebida sob a égide de avanço simétrico, contínuo e com um sentido prévio. A fenomenologia tratou o progresso filosófico não como acúmulo de informações, mas como aprofundamento dos problemas em torno ao fundamento extra temporal presente na criação filosófica. Ele explicou o significado desse entendimento num Discurso na Academia de Ciências de Lisboa onde afirmou (1992): 'Não há filosofia sem filósofo, e pode mesmo dizer-se que cada filosofia tem sua data, à despeito do plano extra temporal inerente à criação filosófica" (p. 356). Quanto à raiz 
fenomenológica do procedimento está afirmada na Introdução à Filosofia como ciência de rigor do seguinte modo (1981):

Em sintese, Husserl coincidiu em parte com Dilthey em reconhecer a existência do elemento histórico como inerente à constituição humana, dado o homem ser consciência do seu passado, e, portanto, atribuir à história, isto é, às ciências do espírito, a função de proporcionar a compreensão da estrutura morfológica da arte, da religião e da filosofia enquanto criações culturais. (p. 495)

Husserl entendia a filosofia como a ciência por excelência e acreditava que o superável em cada filosofia é o que nèla havia da ciência de seu tempo. Essa forma de lidar com as teorias filosóficas sugerida por Husserl, Joaquim de Carvalho usou nos seus estudos de história da filosofia, afirmou-o em Saber e Filosofia (1981) do seguinte modo:

Bacon sentiu a exigência racional de um Novum Organon coerente com a ciência nova que alvorecia e numerosos lógicos contemporâneos se esforçam hoje por estabelecer a formação de um novíssimo organon, coerente com os progressos das matemáticas e das ciências exatas. (p. 374)

O vínculo com a ciência é o que torna superável o trabalho do filósofo. Essa interpretação sugere que um filósofo grego, Platão, por exemplo, não é menos profundo, nem sua filosofia mais incompleta que outra mais moderna, como a interpretação de Hegel sugere. O falível na filosofia platônica é o modo como ela incorporou a ciência do seu tempo. No restante ela pode ser expressão maravilhosa do extra temporal ou universal procurado pela filosofia em sua jornada histórica.

\section{A fenomenologia e a alma portuguesa}

No ensaio As contribuições de Joaquim de Carvalho para as relações filosóficas luso-brasileiras (2000) mostramos outro aspeto da influência fenomenológica no modo de trabalhar de Joaquim de Carvalho. Não se trata mais de olhar as relações entre as diversas filosofias, mas examinar como um problema foi visto por diferentes pensadores, como ele foi aprofundado e entendido ao longo da tradição filosófica.

Como pudemos indicar no ensaio acima mencionado, a saudade é um problema importante para a filosofia portuguesa na avaliação de Joaquim de Carvalho (2000):

Joaquim de Carvalho entende que entre os problemas fundamentais da filosofia portuguesa está a saudade. Desde o século XV, preocupa-se com a significação, o sentido e o valor da saudade, mas é a partir do século XIX que ela se torna objeto específico do filosofar [...]. Ela influi na escolha dos objetos que nos cercam. (p. 28) 
Joaquim de Carvalho usa referências da fenomenologia para descrever a saudade em $A$ alma portuguesa. Ali a apresenta como um aspeto da existência humana (1987): "uma relação valorativa entre a situação que atualmente vive e a situação outrora vivida e de senti-la como desvio agradável ou desagradável do fluir da existência" (p. 111). O professor de Coimbra indica que a palavra saudade encontra um eco distante no advérbio latim solu, o que significa que o termo tem embutido a consciência de estar só. Em outras palavras a saudade é, para Carvalho, reveladora da solidão ontológica. Essa consciência não se limita ao isolamento físico da pessoa, mas alcança "aquele estado de alma de se sentir só, pelo que o termo genérico solu se explicitou na particularização das ideias que exprimem o sentido da solidão e solitude" (p. 108). A solidão ontológica exprime a singularidade existencial porque a consciência que pensa um objeto com ele estabelece um encontro particular. Não apenas é tarefa de cada homem pensar filosoficamente por que o mundo lhe afigura como único, mas o pensar só é autêntico se expressa o sentido de uma vida original e única. Assim a fenomenologia foi a inspiração de Joaquim de Carvalho para enxergar a saudade como identificadora da condição essencialmente solitária de cada homem. A saudade compõe a singularidade existencial porque situa cada homem no tempo de um modo único, o que o obriga a avaliar pessoalmente tudo o que vive. É essa realidade fundamental que Luijpen identifica como a grande contribuição da fenomenologia existencial quando afirma (1973):

Toda vida só é autenticamente humana quando ele próprio (cada homem) a vive. O filosofar só é legítimo filosofar quando o homem próprio filosofa, quando ele próprio suscita perguntas, quando ele próprio procura respondê-las, quando ele próprio procura vencer os óbices do conhecimento. (p. 18)

Esse vínculo entre solidão e singularidade pessoal mencionado por Joaquim de Carvalho e descrito por Luijpen foi reconhecido por Vicente Ferreira da Silva em sua teoria da solidão. Ferreira da Silva mostra que a solidão abre o caminho para o encontro com outros eus, para a intersubjetividade, mas revela, sobretudo, que solidão é um fenômeno percebido pela consciência humana porque ela tem uma relação íntima com o mundo, algo que é somente humano como esclarece no texto citado (1966):

Fala-se comumente na solidão das praias, em palmeiras ou bosques solitários. Essas expressões são, entretanto, meras metáforas, pois somente o homem pode ser solitário. As coisas são exterioridade pura, incapacidade de recolhimento e de auto distanciamento. $O$ que é a natureza senão essa grande contiguidade, essa imensa conexão vital donde nada pode ausentar-se? Unicamente o nosso ser, como não coisa, como excedente à natureza, como espírito, pode produzir-se como destino solitário e distante. (pp. 98-99) 
Joaquim de Carvalho afirma que saudade é uma questão importante para os portugueses há muitos séculos, mas que foi com Teixeira de Pascoais que ela adquiriu densidade filosófica. A interpretação joaquimita do legado de Pascoais mostra clara influencia fenomenológica. Ele diz que Pascoais reconheceu que a ciência pode tratar do homem, mas não o capta integralmente. A existência não pode ser alcançada pelo discurso da ciência, ela tem a ver com a liberdade, com nossas escolhas. Diz Carvalho que é o inconformismo com a redução da vida aos enunciados da ciência, que levou Pascoais a ir além da fenomenalidade das coisas. A interpretação de Carvalho está claramente marcada pela noção de crise da ciência e pela noção dos estratos indicados por Husserl. Ele diz que Pascoais trabalha com quatro intuições fundamentais (2000):

A primeira é a irredutibilidade do mundo racional da ciência ao da vida, a segunda é o reconhecimento da hierarquia dos seres, situando cada qual num ponto; a terceira proclama a superioridade do espírito sobre o mineral, o vegetal e o animal na hierarquia do mundo; e a última apresenta a saudade como a suprema expressão do homem. (p. 28)

A descrição acima mostra que Joaquim de Carvalho identifica em Pascoais uma aglomeração de seres que pode ser organizada na consciência da mesma forma que Husserl fazia. Essa maneira de ordenar os seres Husserl denominou de ontologia material. Ela nasce como produto das vivências da consciência intencional. Trata-se de reconhecer a existência de vários blocos "voltados ao estudo da natureza, da vida e da história". ${ }^{3}$ Essa ontologia se contrapunha, na fenomenologia, à formal que reunia diferentes categorias propostas por axiomas universais.

\section{Considerações finais}

Um dos aspetos fundamentais da reflexão filosófica de Edmund Husserl é elevar a Filosofia à condição de ciência rigorosa. Essa iniciativa se explica pela formação matemática do filósofo. $\mathrm{E}$ a maneira de aplicar esse propósito à história da filosofia foi focar nos problemas, tomando-os como base segura para avançar na direção do que havia de intemporal no filosofar. Joaquim de Carvalho aplicou essa referência nos seus estudos de história da filosofia privilegiando os problemas. O que o historiador devia buscar com atenção, entendeu, era aquilo que o filósofo tinha como imediatamente dado à sua consciência. A volta a esse elemento era possível de ser feita inúmeras vezes, o que

${ }^{3}$ Carvalho, 1999, p. 49 
supera a ideia de uma história da filosofia progressiva, cumulativa, unilinear como sugeriram Hegel e os positivistas. Uma história da filosofia de inspiração fenomenológica representa a superação da leitura hegeliana e positivista da história cujo exemplo é o trabalho de Joaquim de Carvalho.

A partir da inspiração husserliana, Joaquim de Carvalho construiu uma história da filosofia pensada rigorosamente, mas onde seu agente permanece livre e com uma vida de risco. O caráter rigoroso do estudo fica assegurado pela redução fenomenológica que vai adiante da forma temporal de pensar filosoficamente.

Outro aspeto da fenomenologia presente nos estudos de Joaquim de Carvalho se mostra em estudos temáticos como os que fez sobre a liberdade e a saudade. Nesse último, em particular, se revela a consciência da solidão ontológica própria de todo homem. No estudo sobre a saudade Carvalho faz a redução eidética, colocando os fatos entre parênteses e descrevendo a sua estrutura de sentidos. Essa atitude eidética é uma forma alternativa de tratar os fenômenos diversamente da mentalidade positivista que mira os fatos como objetos quantificáveis, idealizando o mundo. Na descrição da saudade a relação deixa de estar no núcleo de dissensão dos pólos epistêmicos para se apresentar na interação consciência-mundo. Assim, Carvalho encontra-se no espírito fenomenológico entendendo consciência como consciência de algo, do mesmo modo que trata a consciência como intencionalidade dirigida a objetos.

Quer nos seus estudos de história da filosofia, quer em sua abordagem temática, procuramos demonstrar que Joaquim de Carvalho adota posições da fenomenologia de Husserl.

\section{Referências}

Brito, António (2010). Notas sobre o aparecimento da fenomenologia em Portugal. In: Maria Celeste Natário, António Braz Teixeira \& Renato Epifânio (Coords.), O movimento fenomenológico em Portugal e no Brasil. Sintra: Zéfiro.

Carvalho, Joaquim de (21992 [1978]). Discurso na Academia de Ciências de Lisboa.

In: Obras Completas. Vol. I, pp. 355-365. Lisboa: Fundação Calouste Gulbenkian.

CARVAlHo, Joaquim de ( ${ }^{2} 1992$ [1978]). Antero de Quental e a filosofia de Hartmann. In:

Obras Completas. Vol. I, pp. 409-431. Lisboa: Fundação Calouste Gulbenkian.

Carvalho, Joaquim de (1981). Saber e Filosofar. In: Obras completas. Vol. II, pp. 355-376. Lisboa: Fundação Calouste Gulbenkian.

Carvalho, Joaquim de (1981). Discurso em Braga. In: Obras Completas. Vol. II, pp. 430-436. Lisboa: Fundação Calouste Gulbenkian.

CarvalHo, Joaquim de (1981). Introdução à Filosofia como ciência de rigor. In: Obras Completas. Vol. II, pp. 473-503. Lisboa: Fundação Calouste Gulbenkian. 
CARVAlHo, Joaquim de (1987). A alma portuguesa. In: Obras completas. Vol. V, pp. 105-138, Lisboa: Fundação Calouste Gulbenkian.

Carvalho, Joaquim de (1989). Pensamento Político. In: Obras completas. Vol. VI, pp. 255-294. Lisboa: Fundação Calouste Gulbenkian.

CARVALHO, José Maurício de (1999). Filosofia da cultura. Porto Alegre: EDIPUCRS. CARVALHo, José Maurício de (2000). A filosofia política, Joaquim de Carvalho e a liberal democracia. Anais de Filosofia. São João del-Rei: UFSJ, 7: 101-114, julho.

Carvalho, José Maurício de (2000). A contribuição de Joaquim de Carvalho para o incremento das relações filosóficas luso-brasileiras. Paradigmas. Londrina: EDUEL, 4(1): 23-34, dezembro.

CARVAlHo, José Maurício de (2001). História da Filosofia e tradições culturais, um diálogo com Joaquim de Carvalho. Porto Alegre: EDIPUCRS.

Carvalho, José Maurício de (2007). O Homem e a Filosofia. Porto Alegre: EDIPUCRS.

LÉVINAS, Emmanuel (1949). En découvrant l'existence, avec Husserl et Heidegger. Paris: Vrin.

LUIJPEN, W. (1973). Introdução à fenomenologia existencial. São Paulo: EPU.

\section{ABSTRACT}

The paper studies the contribution of Joaquim de Carvalho, a teacher at the University of Coimbra in the first half of last century, to the phenomenological movement in Portugal. Its importance is not restricted to the introduction he had prepared for the Portuguese translation of The Philosophy of rigor as science. He used the lessons of Edmund Husserl to build a critique of Hegelian and positivist conceptions in his work History of Philosophy. It also draws on phenomenology to treat problems such as homesickness. All these aspects of the project as publisher of phenomenology in Portugal, especially in education. 